\title{
Plenary Session Evaluator (PSE): A Problem Oriented Based Learning Approach
}

\author{
Iqbal Uddin Khan, Qazi Muhammad Fuzail, Muhammad Danish Afzal, \\ Faizan Hussain, Afzal Hussain
}

\begin{abstract}
The aim of this paper is to proposed a platform that has the primary objective regarding the ease factor of end-users. An issue has been inspected on several platforms regarding the individuals that they feel hesitated, shy, and dithered while asking and sharing their opinions, suggestions, feedback, queries, etc. Such a stance occurs when there are a lot of people in their surroundings. It ultimately reflects on effectiveness and productivity in a particular domain. To mitigate such issues in order to attain high-quality artifacts researchers proposed a mechanism that helps in facilitating the people to eradicate their shyness and hesitation in domains while asking questions and queries or giving any suggestions or feedback through the technological medium which is Plenary Session Evaluator.
\end{abstract}

Index Terms - Ask your mind, Quiz session, Session evaluator, Website, Android, Education, Productivity, and Usability.

\section{INTRODUCTION}

As per the research of [1], the significance, momentum, and rapid progression of technology have an adequate upsurge which is growing with time adequately. Moreover, due to the technological advancement in the modernization era, several applications and platforms are developed which effectively assisting, facilitating, and supporting the end-users to achieve their goals passably. In addition, to become advanced and efficient along with the provision of sufficient factors of ease, modernization era and technologies are playing an active role in supporting people by focusing on the POBL (Problem Oriented Based Learning) approach. Furthermore, [2] defines that the ease factor which is helping the end-users is aimed towards the usability and usefulness facets to attain high-quality outcomes. According to [3] in modernization era the demands, needs, wants and worries of people have been modified and changed which is considered as one of the primary reasons that ultimately support the researchers, scholars, or authors to identify, elucidate, and investigate those demands, needs, wants, and worries and proposed and discussed several useable and essential platforms that could be helpful for the end-users in terms of conformance to their requirements.

Iqbal Uddin Khan, Faculty of Engineering Science and Technology FEST, Hamdard University Karachi, Pakistan

Qazi Muhammad Fuzail, Faculty of Engineering Science and Technology FEST, Hamdard University Karachi, Pakistan

Muhammad Danish Afzal, Faculty of Engineering Science and Technology FEST, Hamdard University Karachi, Pakistan

Faizan Hussain, Faculty of Engineering Science and Technology FEST, Hamdard University Karachi, Pakistan

Afzal Hussain, , Faculty of Engineering Science and Technology FEST, Hamdard University Karachi, Pakistan
[4] defines that technological advancement is playing a vital role in solving the issues and problems of people. [5] discussed that with time technology has been getting more advanced compared to its initial era and it is instantaneously modifying its process, methods, approaches, and design which support the people in an effective manner. However, [6] define that numerous aspects have been developed under the umbrella of technology which had a primary agenda to provide the usability and usefulness aspects to end-users. Moreover, ease factors are developed in the form of tangible or intangible sources such as the internet, mobile application, web applications, QR codes, IoT and several others; however, it can be stated that they are aimed towards the provision of solving problems of end-users. Additionally, [7], has delineated that technological advancement and modification in the modernization era have been notifying in different domains and vicinities. Such vicinities and domains are either related to health care, hospitality, education, management, business, and various others. Furthermore, [8] has posited that in these vicinities' technology is playing a vigorous role, in hospitality managing the records, provision of services is sufficiently achieved along with customer satisfaction. In management four-pillar such as planning, monitoring, organizing, controlling is executed adequately. In healthcare advanced mechanisms and systems which is playing an essential character in providing the healthcare services sufficiently; thus, in numerous fields, technology, and its different trends and application have made remarkable prominence. Adhering to the educational vicinity technology and its diverse trends and applications which are beneficial in facilitating learners with numerous significant facets which ultimately helping learners and educators in accomplishing the aims along with becoming more productive, industrious, and creative. Therefore, technology and its various trends and applications are beneficial, which supports and helps people effectively and efficiently.

Although technology and numerous vigorous factors are adequately helping the learners and educators effectively, there are some significant issues in an educational institution that are associated with the learners that are not resolved yet. It is necessary that such issues must be underlined and discussed along with the solution which eventually helps in attaining quality outcomes [9]. The issues which have been discussed by the researchers are common in every generation either it is Generation X, Y, or Z; although the mechanisms of teaching and learning have been modified from the book towards E-Sources. However, the issues of shyness and hesitation are common which negatively impacting on the productivity and efficiency of the learners $[10,11,12]$. Fig .1 
delineates the layout of this paper.

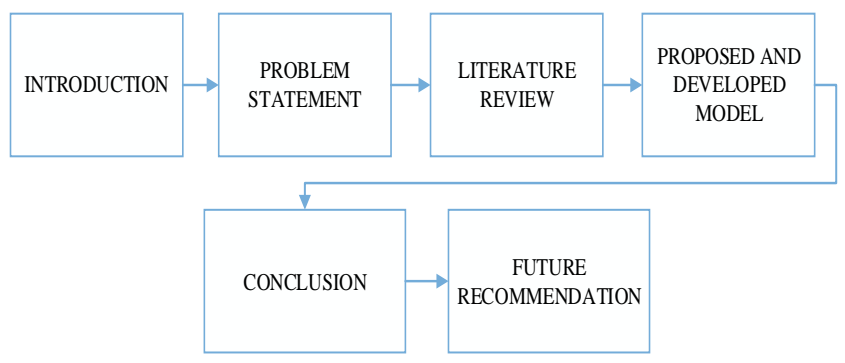

Fig .1 Layout of Paper.

\section{PROBLEM STATEMENT}

This proposed section of the paper is deliberating the main problem on which the paper is grounded. The paper is constructed on POBL (Problem Oriented Base Learning) phenomena along with the educational institutions and leaners. In the modern era of technology, the primary and most important thing is to make end-users to understand different aspects better that help them in becoming productive and efficient. However, this ultimately supports the attainment of quality artifacts. In order to so, it is obligatory to have clarity in mind that further helps in accomplishing the endeavors passably. Learners or end-users sometimes have questions and queries in their minds after the sessions as mentioned earlier, but due to lack of confidence, shyness, hesitation they do not ask questions. Therefore, this negatively impacts the learner credibility's, audacity, and capability in the educational institutions, which has been further analyzed from the questionnaire results. Moreover, to underline issues the researchers have adopted primary data collection such as Likert scale questionnaire survey and open-ended questionnaire which has been conducted in the educational institution with 50 students to effectively discussed the undiscussed issue of educational institutions. Fig .2 - Fig .5 illustrates the Likert scale questionnaire survey results whereas, Fig 6 is illustrating the open-ended questionnaire results. Therefore, both questionnaires are based on four questions.

Question: 01 Do you feel shy in your classroom?

\section{Do you feel shy in your class room?}

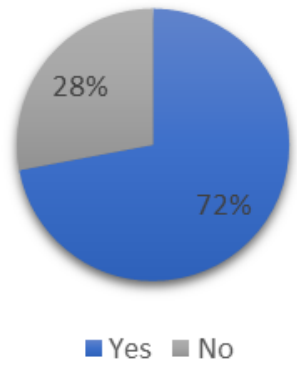

Fig .2 Likert Scale Question 01 Results

Question: 02 Do you believe that your shyness and hesitation negatively impacting the productivity of learners in educational activities?
Do you believe that your shyness and hesitation negatively impacting productivity of learners in educational activities?

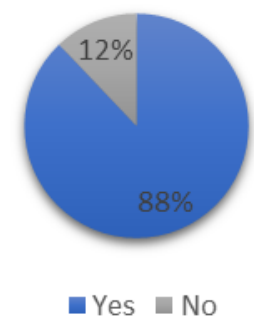

Fig .3 Likert Scale Question 02 Results

Question \#03 Why you feel shy and hesitate in classrooms?

\begin{tabular}{|c|c|}
\hline \multicolumn{2}{|c|}{$\begin{array}{c}\text { Why you feel shy and hesitate in } \\
\text { classrooms? }\end{array}$} \\
\hline $\begin{array}{l}\text { Due to lack of intrest in the } \\
\text { topic }\end{array}$ & $7 \%$ \\
\hline $\begin{array}{l}\text { Due to the Query you have in } \\
\text { your mind }\end{array}$ & \\
\hline Due to Confidence & \\
\hline
\end{tabular}

Fig .4 Likert Scale Question 03 Results

Question \#04 Do you think that in the current epoch where technology is cultivating enormously, there must be a solution which helps learners in such aspect?

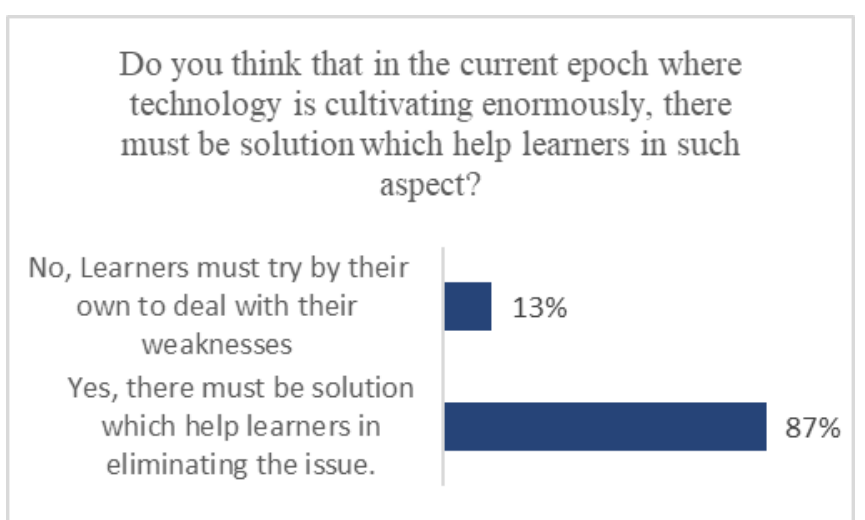

Fig .5 Likert Scale Question 04 Results

Furthermore, after identifying the responses of leaners significantly, the researchers of this paper have discussed and developed a solution that ultimately helps in the abolishment of those issues which is known as PSE. PSE is a solution based on the current technological aspects which help the learners and educators to adequately communicate with each other. In addition, researchers have also conducted an open-ended questionnaire survey in which the motive was to assimilate the information regarding the PSE and its impact on the learners. 50 learners were selected for open-ended questionnaires; however, Fig .6 addresses the no of participants who have participated in the open-ended questionnaire survey. Thus, the responses of participants have also been quoted by the researchers. 
R1: "We do feel shy and hesitated in our classrooms while asking any query because we think other learners will make fun of my question".

$R 1$ responses have been given by 18 learners out of 50 . Another response 22 of leaner has been quoted below which has been answered by 06 learners;

R2: "Sometimes due to shortage of time, educators do not passably answer the question which ultimately makes our concepts ambiguous."

06 of the respondents (R3) stated that;

R3: "We live in the modern tech age where diverse platforms are developed frequently, but there is not as such a platform which provides the solution to this enormous problem."

While concluding the survey, the author has defined the concept of PSE, on which the 20 of the participants have responded that;

R4: "PSE will be the satisfactory platform which helps in solving such enormous issues, its functionality of covering the short time issues and hesitation aspect would adequately help us to perform better in our academic activities along with securing good grades."

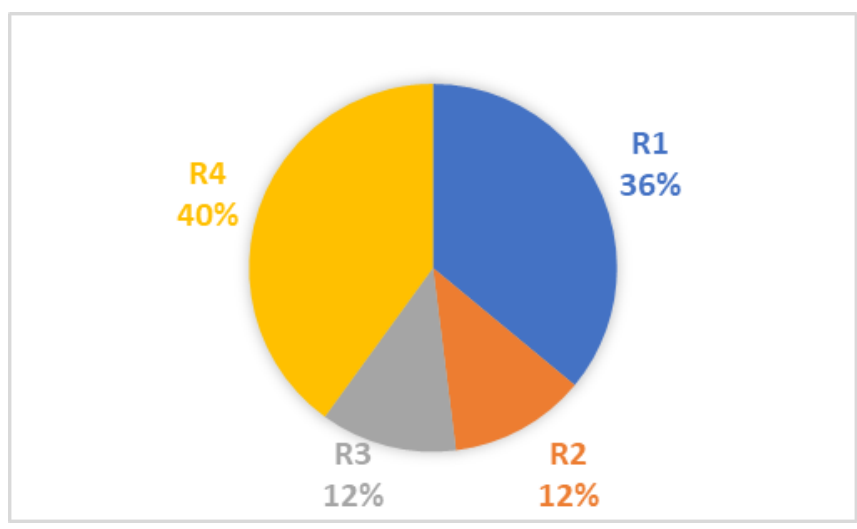

Fig .6 Open-Ended Questionnaire Results

Therefore, after gathering the responses in the close and open-ended questionnaire it can be stated that PSE will play a vital character in becoming a bridge among educators and learners, which helps in solving the identified issue. Fig. 5 illustrates the results graphically. Consequently, researchers of this paper are emphasized on the eradication of such identified issues from educational institutions. The researchers further focused on technological advancement, trends, and applications to develop a platform which helps in eradicating the identified issues adequately. In order to do so, the researchers proposed and developed a system, mechanism, or platform which is known as Plenary Session Evaluator (PSE). PSE is based on the two vital essentials of technology and modernization era such as mobile and web applications and platforms. However, the upsurge of mobile applications and web platforms is noteworthy among learners. Therefore, PSE is developed on both mechanisms, along with focusing on usability, usefulness, effectiveness, reliability, robustness, and efficiency facets. Thus, the block diagram of PSE has been portrayed in Fig. 7 to develop the necessary understanding for the readers.

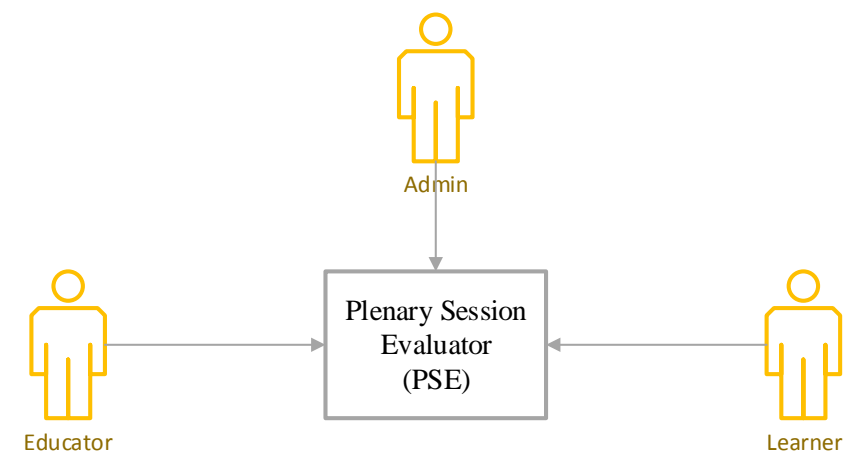

Fig. 7 Block Diagram of PSE.

\section{LITERATURE REVIEW}

According to the author of the [13] the researcher has observed that the character-level encoder-decoder systems can be effectively connected to address replying with an organized information base. In addition, use our model for single relation question noting and show the viability of our methodology on the Simple Questions dataset where improve cutting edge precision from $63.9 \%$ to $70.9 \%$, without the utilization of outfits. Critically, our character-level model has 16x fewer parameters than a proportionate word-level model, can be educated with substantially less information contrasted with past work, which depends on information expansion, and is hearty to new elements in testing.

Moreover, [14], posited that attending English conversation classes and motivating foreign language theories has been an essential topic in language learning for over four decades. Oral communication in English is supposed to be necessary for working life. Since learning a new language is a challenging issue for most English as a Foreign Language (EFL) learners as well as English as a Second Language (ESL) learners, confidence in learning plays a vital role for learners to learn. Improvement of one of the crucial skills in "spoken" language learning, although this has been ignored in traditional methods. The purpose of this review is to demonstrate the implementation of extensive experience that would be very useful for educators involved in teaching EFL / ESL. Due to the significant difference between young learners and adults, educator awareness can significantly help them in their profession. It is strongly recommended that learner motivation and the good relationship between learners and the class educator actively support learner performance by participating in oral tasks. In addition, the tools and methods an educator selects to promote learners' oral activities are greatly improved.

In the research of [15], it has been identified that the rise of the meaning of contemplative practices inside the field of educator instruction has brought about a more noteworthy requirement for understudy instructors to consider the viability of their instructing practices to meet the expanded dimensions of responsibility that is related with their expert advancement. This paper gave an examination of the potential commitment of reflection for the advancement of compelling showing abilities among understudy educators during the practicum course by using both quantitative and subjective research techniques. This paper meant to consider the potential connections between contemplative practices and expert advancement of understudy educators. Paper 
likewise looks at the intelligent practices of understudy educators. The outcomes uncovered that reflections on expert practices bolstered understudy instructors to improve their relations with understudies and partners. Understudy instructors revealed that they got mindfulness; they had the option to comprehend the information in real life which improved understudy educators' abilities for the conveyance of exercise during practicum.

According to [16] This is a replication of an examination that analyzed the impacts of instructing establishment capabilities in gathering work to social work understudies and surveyed their self-assurance in applying these aptitudes. This investigation enhances the first by using a controlled plan. Twenty-six ace of social work understudies were instructed gathering work capabilities got from the International Association for the Advancement of Social Work with Groups' (IASWG) Standards for Social Work Practice with Groups utilizing pedantic exercises, and smaller-scale aptitude works out. Understudies were surveyed multiple times on their trust in gathering work abilities utilizing an approved 70-thing stock. Gathering work abilities were isolated into three squares and instructed progressively in a shortened various gauge structure. The t-tests showed critical increments in certainty evaluations in the wake of preparing on the separate aptitudes yet not before abilities preparing. The outcomes give extra help to the adequacy of the instructing approach in structure understudy trust in utilizing IASWG Standards.

\section{WORKING AND IMPLEMENTATION}

In this section, the authors have profoundly conducted a detailed and descriptive discussion with regards to the PSE, its processes, functional requirements, and other utmost essential facets. In the modern education system, PSE allows learners to connect and collaborate with the educator and the course in a unique way to enhance the understanding and eradicate any delusion thought that a learner might have in their mind. Furthermore, it is analyzed that there are lots of questions in the minds of learners after the class, but the educator does not get enough time to answer all of the questions. Also, sometimes learners to feel vacillated while asking any query. Therefore, the proposed system PSE will include an anonymous question-answer system through which a learner will ask the question without any hesitation, and educators will know where they are having the problem conveying the topic. Furthermore, this system will be executed by the educators themselves near before the end of the session through a unique barcode which will be generated by the system according to the specific time of the session and let the attendee join the session just by reading the barcode.

\section{A. Aims and Objectives of PSE}

In order to facilitate the learners in educational institutions to become productive, creative, and innovative PSE system has been proposed and developed by the authors. In addition, the system is grounded on some aims and objective to attain high-quality outcomes mentioned below;

- The main objective of the project is to enhance the effectiveness of teaching and learning procedures around the world.
- The objective is to make an android application to get all the information in an individual's reach.

- The objective is to get all the participants and the lecturer in one place to provide active learning and teaching

- Responsive websites for learners and educators to correspond with each other for questions and answers.

- Android Application for learners to use the portal for questions and quizzes within the class.

- Session feedback report generation.

- Learners will be provided with the multiple-choice question quiz related to that session which will be held in the last 10 minutes of the class/lecture.

- Prerecorded MCQs will be submitted by the educator before the session through which the program will match the right or wrong answers and generates the session evaluation report according to the results.

- All questions and answers will be recorded and available at the portal always for learners to understand the lecture more effectively.

- An educator can record Audio response on the portal.

- An analysis algorithm will be used to analyze and generate the performance report of the previous classes.

- The system will collaborate with CMS (Campus Management System).

Additionally, the block diagram mentioned in Fig. 1 has been modified in this section to developed the basic understanding with regards to the functional requirements of PSE. Fig.04 is illustration such necessary modification.

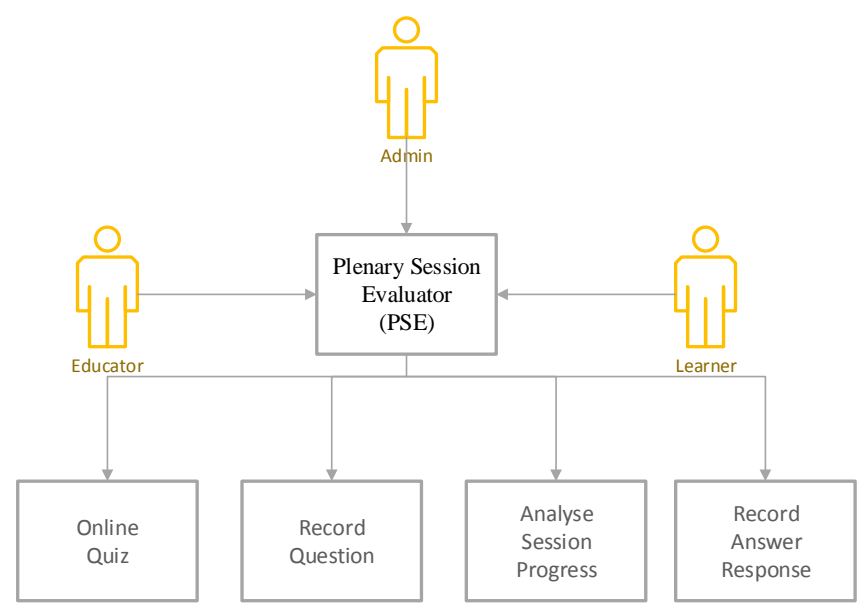

Fig.8 Modified Block Diagram

Plenary Session Evaluator (PSE) is targeting educational domains. Plenary Session Evaluator proposed the easiest and the most indirect way of asking questions from educators and the lecturer to clear the concept of the session. The project is based on android and web platforms. There are two main characters in PSE Learner and Educator. However, since PSE is focused on the educational domain and providing the core facility of making communication better among learners and educator it is further supported by Admin. Learners will ask their questions anonymously from the educator by using an android or web application which will lead them to the portal and where they were already registered. Educators and learners will be automatically registered through CMS (Campus Management System). Learners will be facilitated with the username and password given by the administration 
or admin module which will allow the restricted learners who are registered in the course to access the portal and submit their questions which will anonymously appear on the portal of the educator in the last five minutes of the session. The educator will answer the questions as much as he/she can at the time of the class, and then the remaining will be answered after the class. The benefit and effectiveness of PSE are that while the learner is absent, he/she can easily access all the discussion of the class using the PSE portal either using the web or android application. An educator can record the answer after the class and upload it on his portal concerning questions. Simultaneously, Table .01 is highlighting the basic understanding of PSE functionality. A comparison of the traditional process and PSE has been mentioned in the table in order to outline the benefits.

Table.01 Comparison of PSE and Traditional Approach

\begin{tabular}{|c|c|c|}
\hline Factors & PSE & $\begin{array}{l}\text { Traditional } \\
\text { Approach }\end{array}$ \\
\hline $\begin{array}{l}\text { Asking } \\
\text { question }\end{array}$ & $\begin{array}{l}\text { The learner will ask a } \\
\text { question by their } \\
\text { smartphone one at a } \\
\text { time }\end{array}$ & $\begin{array}{l}\text { Learners will ask } \\
\text { questions all at once and } \\
\text { will not be understood by } \\
\text { the educator }\end{array}$ \\
\hline $\begin{array}{l}\text { Answer } \\
\text { questions }\end{array}$ & $\begin{array}{l}\text { The educator will } \\
\text { upload the answer after } \\
\text { a thorough search and } \\
\text { understanding in free } \\
\text { time }\end{array}$ & $\begin{array}{l}\text { The educator will not get } \\
\text { enough time to answer all } \\
\text { the questions and may } \\
\text { forget the remaining } \\
\text { questions }\end{array}$ \\
\hline Quiz & $\begin{array}{l}\text { The educator will } \\
\text { upload the quiz and } \\
\text { execute it with barcode }\end{array}$ & $\begin{array}{l}\text { The educator will have to } \\
\text { read the quiz and print } \\
\text { before the class and } \\
\text { distribute to all the } \\
\text { learners }\end{array}$ \\
\hline $\begin{array}{l}\text { Quiz } \\
\text { results }\end{array}$ & $\begin{array}{l}\text { The system will check } \\
\text { the quiz and give marks } \\
\text { to the learners }\end{array}$ & $\begin{array}{l}\text { The educator will collect } \\
\text { all the papers and } \\
\text { manually check them one } \\
\text { by one }\end{array}$ \\
\hline $\begin{array}{l}\text { Session } \\
\text { evaluator }\end{array}$ & $\begin{array}{l}\text { According to the results, } \\
\text { the system will let the } \\
\text { educator know which } \\
\text { topic is not cleared }\end{array}$ & $\begin{array}{l}\text { The educator will have to } \\
\text { check manually what part } \\
\text { of the lecture was not } \\
\text { delivered to learners }\end{array}$ \\
\hline
\end{tabular}

\section{B. PSE System Design}

To adequately explain the system design and its process, the authors have adopted the UML (Unified Modeling Language) approach [17]. The rationale behind adopting the UML approach is to deliver the understanding concerning every functionality of PSE. This ultimately helps the readers in understanding the flow of PSE. As it has been mentioned earlier that there two main actors who are learners and educators supported the admin of educational institutions to have a proper monitored, and synchronized process. Thus, each has a different role and responsibility which has been addressed in Fig. 9, Fig.10, and Fig.11.

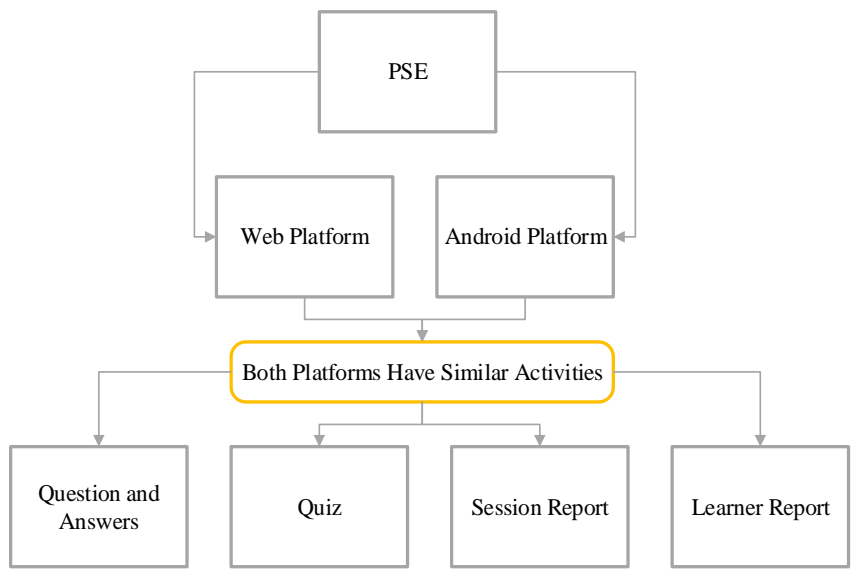

Fig.9 PSE and Platforms

1) System Flow for admin: Admin plays a vital role in acquiring high-quality communication among learners and educators. It helps in monitoring the synchronizing process. Since, it is an educational institution the admin role is to confirm the basic needs, such as registered educator and registered learner of a particular class, along with the educator and course allocation which is a necessary facet in the educational domains due to annual and semester system. Further added to the argument courses, educators, and learners are changed according to the classes, semesters, and annual system. In order to monitor, control and manage such essential requirements admin will be beneficial to do so. Moreover, an admin will also helpful in the learner's and educators' cases such as if they leave the educational institution, or due to any other stance they are not available either for a long or short time their actions must be paused or eliminate. In addition, it will also admin can block or unblock learners if the educator will notify the admin of unwanted words. This is necessary to manage the application process time, especially when several learners and educators are communicating with each other.

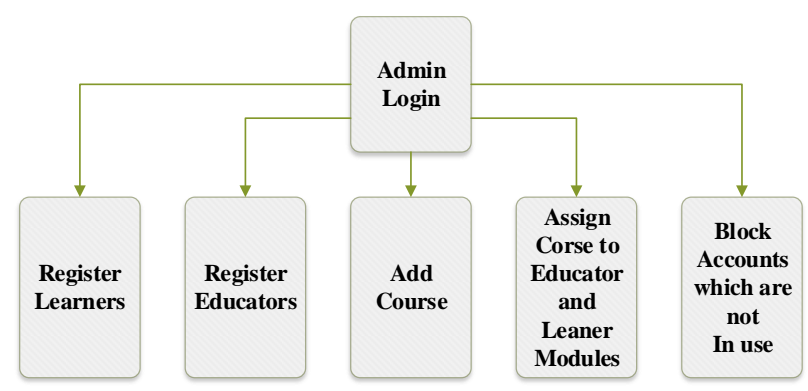

Fig.10 Admin System Flow

2) System Flow for Learners: The learner will be facilitated with a QR code on smartphones PSE application, that will be generated by the educator on the board by which they will join the session and ask relevant questions anonymously and after that attempt quiz given by the educator adequately. 


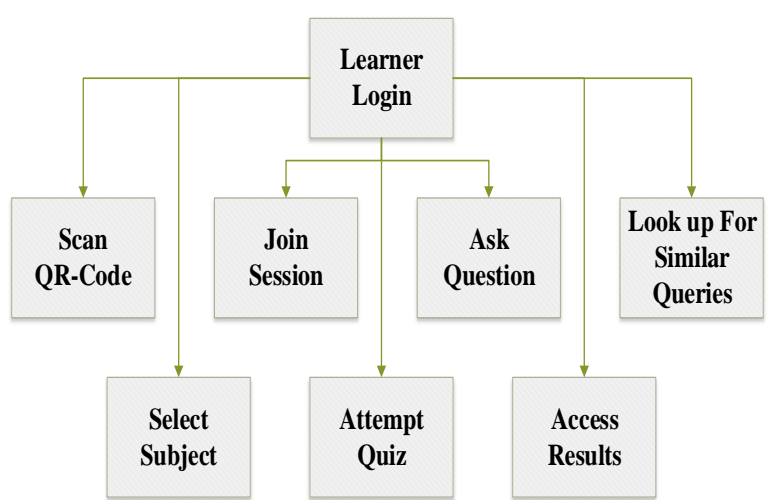

Fig. 11 Leaner System Flow

3) System Flow for Educator: The flow of educator starts with login on Website and create a session that will generate QR-Code for learners in that session to join the session by scanning it with their PSE application in smartphones, educator will get all the questions from learners on the screen and answer them as much as possible and the remaining will be staying there for in order to answer later. Fig 12 illustrates the educator system flow.

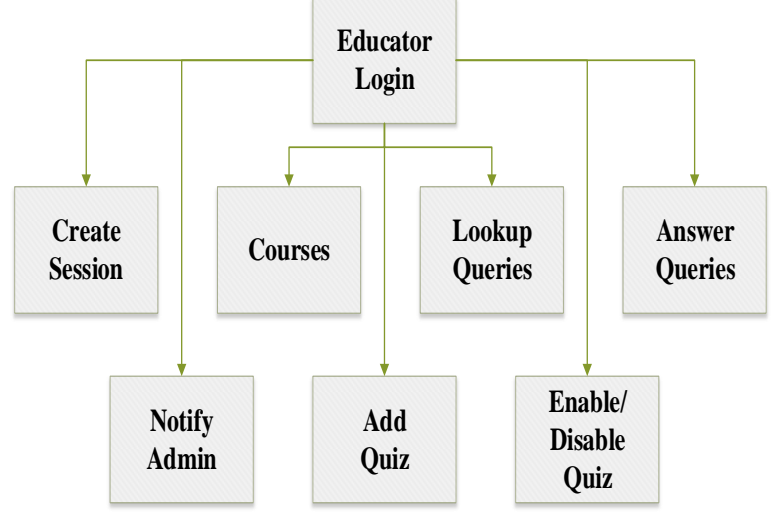

Fig.12 Educator System Flow

4) System Flow for Quiz and Queries: Queries and Quiz are the main functionalities of PSE on which the system flow has been constructed. In both actions' educators and learner's roles, whereas the administration's role is to manage, monitor, and control all the actions in order to attain high-quality outcomes. Moreover, Fig.13 and Fig.14 underline the Queries and Quiz flow to develop the understanding for the readers that how will they proceed in order to achieve the aims and objectives.

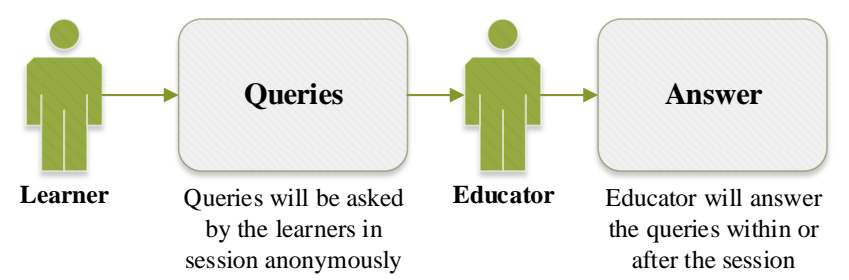

Fig. 13 System Flow of Questions.

The leaner will upload a question relevant to the session for the educator to answer with a hidden identity; the educator then replies to those questions in the class. Moreover, if there is a shortage of time, the question will be on the educator portal, and they can answer them later, either form office or home.

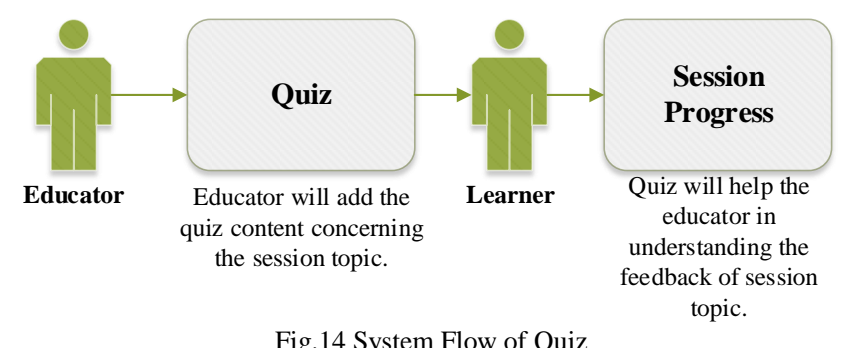

The educator will upload the quiz content in the system according to the session's topic and enable the quiz in the session for Learners. Furthermore, learners will get a specific time to complete the quiz, and then the quiz results will show how effective was the understanding regarding the particular session topic. Therefore, this helps the educator in understanding the learner's response in the class.

5) Use Case Models: The use case shows how actors can potentially act. The actors are entities related to the system and actions are the task they can perform in the system. The use case is one of the types of UML (unified modeling language) $[18,19]$.

\section{a) Use Case of Learner}

Fig 15 is delineating the use case of the learner in PSE.

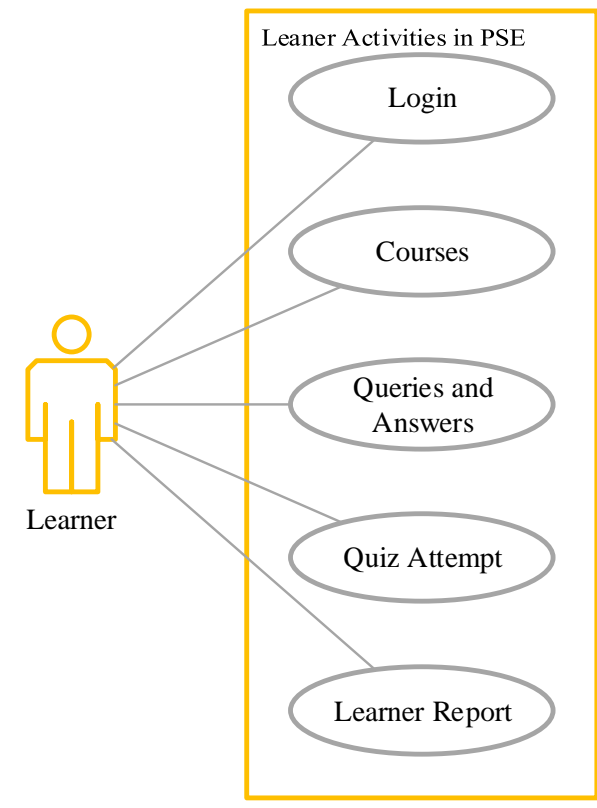

Fig. 15 Use Case of Learner 
b) Use Case of Educator

Fig 16 is delineating the use case of educator in PSE.

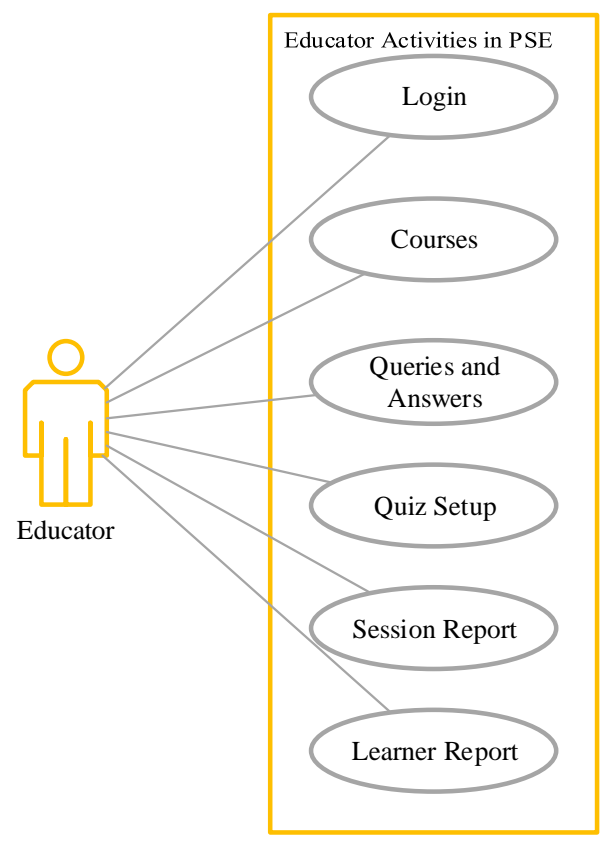

Fig.16 Use Case of Educator

c) Use Case of Admin

Fig 16 is delineating the use case of admin in PSE.

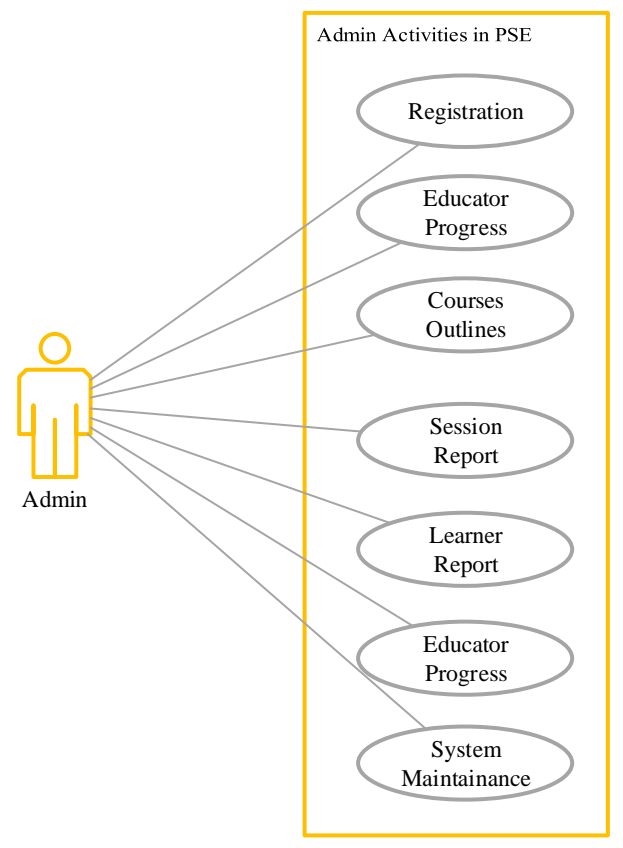

Fig. 17 Use Case of Admin

\section{System Architecture}

This system introduced to facilitate learners and educators, learners can ask questions by joining the session anonymously, and educators can answer all the learners from home and office later without needing to remember the questions. This is because all the questions will be already saved on the portal for the educator to answer later and to other learners who were having some problems in understanding the topic. Similarly, after question and answer educator will enable the quiz which will be given to learners on their smartphones through which they will answer by selecting appropriate answer and the system will automatically generate the quiz results which will show the class progress that how many learners actually understood the topic, whether it was delivered as proper as planned and how many learners could not understand the topic and which part should be repeated.

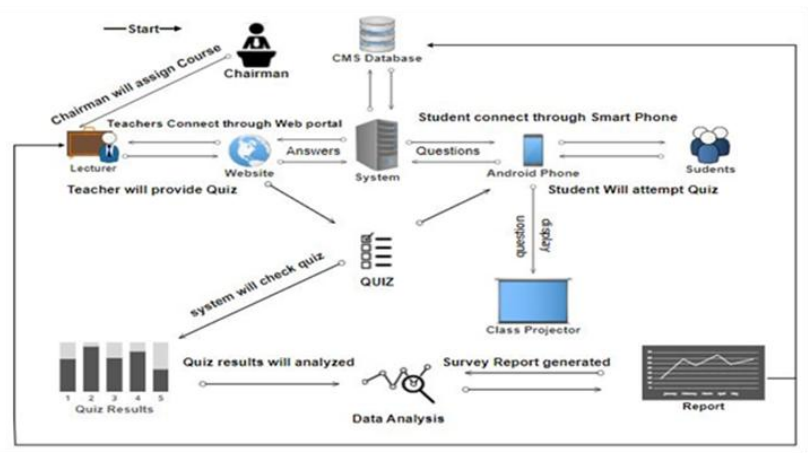

Fig.14 System Architecture

\section{CONCLUSION}

To conclude, Plenary Session Evaluator is an educational portal, developed and proposed on the web and android platforms. Moreover, it has been introduced to automate session evaluation within seconds also this system will help learners who feel dithered to communicate during professional lessons. Moreover, this system allows them to ask questions which are crucial for them to clear their misconceptions regarding the topic. Learners who think their questions are stupid, and hesitate to ask questions in the classrooms can adequately use this system. Simultaneously, on the other hand, educator or the speaker are tied up with a limited time that they could not respond to every question during the session, with this portal educators will respond to all the questions asked during the session from their home or office in free time. The system has unique way of evaluating the session, which sufficient level of understanding of the ratio of the session, that what strength of the class understood the topic. In addition, by a quick Survey quiz that will be extracted from the topic by the educator before the class and posted them to know what part of the topic the majority learner didn't understand, so the educator will be bound to deliver that topic again.

\section{REFERENCES}

[1] Dodgson, Mark. Technological collaboration in the industry: strategy, policy, and internationalization in innovation. Routledge, 2018.

[2] Nikou, Stavros A., and Anastasios A. Economides. "Mobile-Based Assessment: Integrating acceptance and motivational factors into a combined model of Self-Determination Theory and Technology Acceptance." Computers in Human Behavior 68 83-95, 2017.

[3] Xingqing, Ye. "The General Principles of China's Rural Vitalization Strategy in the New Era." Reform 1 65-73, 2018

[4] Tidd, Joe, and John R. Bessant. Managing innovation: integrating technological, market and organizational change. John Wiley \& Sons, 2018.

[5] Cooper, Robert G., and Anita F. Sommer. "The agile-stage- gate hybrid model: a promising new approach and a new research 
opportunity." Journal of Product Innovation Management 33, no. 5 513-526, 2016.

[6] Khan, Muhammad Tanzeel Murtaza, and Junseok Hwang. "Studies on Empirical Investigation of Success Factors for Smart City Implementation." Ph.D. diss., 서울대학교 대학원, 2019.

[7] Pohjosenperä, Timo, Päivi Kekkonen, Saara Pekkarinen, and Jari Juga. "Service modularity in managing healthcare logistics." The International Journal of Logistics Management 30, no. 1 174-194 2019.

[8] Kumar, TM Vinod. "International Collaborative Research: Smart Metropolitan Regional Development: Economic and Spatial Design Strategies and Conclusions of Cities Case Studies." In Smart Metropolitan Regional Development, pp. 1025-1096. Springer, Singapore, 2019.

[9] Dana, Nancy Fichtman, and Diane Yendol-Hoppey. The reflective educator's guide to classroom research: Learning to teach and teaching to learn through practitioner inquiry. Corwin, 2019.

[10] Bradley, Teri A. "Middle School Learners' Experiences in an Online Problem-Based Learning Environment", 2018

[11] Carvalho, Cassandra. "From Page to Stage: Educators' Perception of the Use of In-Role Drama Activities when Exploring Mathematical Word Problems." 2016

[12] Visser, Annemarie. "How do people make sense of their recovery from academic burnout during their undergraduate studies? An interpretative phenomenological inquiry into the experience of young adults." $\mathrm{PhD}$ diss., Middlesex University/New School of Psychotherapy and Counselling, 2019.

[13] D. Golub, "Character-Level Question Answering with Attention," 2014.

[14] A. Derakhshan, "Helping Adult and Young Learners to Communicate in Speaking Classes with Confidence," vol. 6, no. 2, pp. 520-525, 2015.

[15] M. Z. Iqbal, "Professional Reflection a Cradle of Learner Educator's Professional Development," vol. 6, no. 3, pp. 376-384, 2015.

[16] M. J. Macgowan and S. E. Wong, "Improving Learner Confidence in Using Group Work Standards : A Controlled Replication,” 2015.

[17] Karim, Syaeful, Suryadiputra Liawatimena, Agung Trisetyarso, Bahtiar Saleh Abbas, and Wayan Suparta. "Automating functional and structural software size measurement based on XML structure of UML sequence diagram." In 2017 IEEE International Conference on Cybernetics and Computational Intelligence (CyberneticsCom), pp. 24-28. IEEE, 2017.

[18] Torre, Damiano, Yvan Labiche, Marcela Genero, Maria Teresa Baldassarre, and Maged Elaasar. "UML diagram synthesis techniques: a systematic mapping study." In 2018 IEEE/ACM 10th International Workshop on Modelling in Software Engineering (MiSE), pp. 33-40. IEEE, 2018.

[19] Iqbal, Usama, and Imran Sarwar Bajwa. "Generating UML activity diagram from SBVR rules." In 2016 Sixth International Conference on Innovative Computing Technology (INTECH), pp. 216-219. IEEE, 2016. 